\title{
Efficient white and red light emission from GaN/tris-(8-hydroxyquinolato) aluminum/platinum(II) meso-tetrakis(pentafluorophenyl) porphyrin hybrid light-emitting diodes
}

\author{
Hai-Feng Xiang \\ Department of Chemistry and the HKU-CAS Joint Laboratory on New Materials, \\ and Department of Electrical and Electronic Engineering, The University of Hong Kong, \\ Pokfulam Road, Hong Kong SAR, People's Republic of China \\ Sze-Chit Yu and Chi-Ming Che ${ }^{\text {a) }}$ \\ Department of Chemistry and the HKU-CAS Joint Laboratory on New Materials, \\ The University of Hong Kong, Pokfulam Road, Hong Kong SAR, People's Republic of China \\ P. T. Lai \\ Department of Electrical and Electronic Engineering, The University of Hong Kong, Pokfulam Road, \\ Hong Kong SAR, People's Republic of China
}

(Received 14 April 2003; accepted 24 June 2003)

\begin{abstract}
We report efficient white and red light emission from $\mathrm{GaN}$ light-emitting diode (LED)/tris-(8-hydroxyquinolato) aluminum $\left(\mathrm{Alq}_{3}\right) /$ platinum(II) meso-tetrakis(pentafluorophenyl) porphyrin $\left(\mathrm{PtF}_{20} \mathrm{TPP}\right)$ hybrid LEDs. $\mathrm{Alq}_{3}$ was employed to enhance the efficiency of red and white luminescence conversion (LC) LEDs through energy transfer from $\mathrm{Alq}_{3}$ to $\mathrm{PtF}_{20} \mathrm{TPP}$. In the white LC-LED, an intense, highly pure white-light emission with CIE_1931 coordinates at $x=0.32$ and $y=0.31$ is obtained. The LC-LEDs in this work have relatively high efficiencies, $3.3 \%$ for white LC-LED and $4.0 \%$ for red LC-LED. The color temperature $\left(T_{c}\right)$, color rendering index $\left(R_{a}\right)$ and luminous efficiency $\left(\eta_{L}\right)$ of the white LC-LED at $20 \mathrm{~mA}$ are $6800 \mathrm{~K}, 90.6$ and $10 \mathrm{~lm} / \mathrm{W}$, respectively. (C) 2003 American Institute of Physics. [DOI: 10.1063/1.1604192]
\end{abstract}

Recent progress in GaN-based technology has led to the development of bright green, blue, and shorter-wavelength light-emitting diodes (LEDs). ${ }^{1-5}$ White-light LED is particularly desirable as an alternative solid-state lighting source. Using blue or near-ultraviolet ( $n$-UV) light GaN-LEDs as the primary light source, longer-wavelength light emission can be achieved by luminescence conversion (LC) of organic or inorganic dyes. ${ }^{2,6-14}$ The underlying principle is luminescence down conversion (Stokes shift) of the dyes from shorter-wavelength to longer-wavelength emission.

Previous works showed that white-light LED can be fabricated using GaN/conjugated polymer, ${ }^{6,7}$ or GaN/low-molarmass organic ${ }^{2,8-9}$ or inorganic dye [yttrium-aluminumgarnet (YAG)] hybrid materials. ${ }^{8,10-14}$ The conjugated polymers are photooxidatively and thermally unstable, ${ }^{7}$ and the inorganic yellow phosphor (YAG) shows insufficient red emission and low color rendering index $\left(R_{a}\right) .{ }^{13,14}$ In this letter, we report the use of the red dye platinum(II) mesotetrakis(pentafluorophenyl) porphyrin $\left(\mathrm{PtF}_{20} \mathrm{TPP}\right)$, green dye tris-(8-hydroxyquinolato) aluminum $\left(\mathrm{Alq}_{3}\right)$ and $\mathrm{GaN}$-LEDs to achieve white and red LC-LEDs. The chemical structures of the dyes are depicted in Fig. 1.

Commercial n-UV GaN-LED, LC503MUV1-30Q (COTCO), was used as the light pump in the experiments [Fig. 2(a)]. The GaN-LED exhibits a sharp emission at $\lambda_{\max }$ $393 \mathrm{~nm}$ (CIE_1931 chromaticity coordinates: $x=0.17, y$ $=0.02$ ) with an efficiency (light power output/electric power

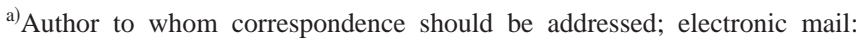
cmche@hku.hk
}

input) of $11 \%$. Beyond the threshold current of $3.4 \mathrm{~mA}$, the output power of the GaN-LED increases linearly with increasing current input. In this work, the red dye $\mathrm{PtF}_{20} \mathrm{TPP}^{15-17}$ was chosen for LED applications ${ }^{18}$ because: (1) it has good solubility in many organic solvents such as chloroform $\left(1.0 \mathrm{dm}^{3}\right.$ chloroform can dissolve more than 20 mg $\mathrm{PtF}_{20} \mathrm{TPP}$ ); (2) it shows an intense red phosphorescence [photoluminescence (PL)] quantum yield of $\sim 12 \%$ in dichloromethane; with full width at half maximum (FWHM) of 26 nm; CIE_1931 of $x=0.72, y=0.28$ [Fig. 2(b)]; (3) there is a strong UV/Vis absorption in hexane (Soret band $\left[\lambda_{\max }\right.$ $\left.=390 \mathrm{~nm}, \varepsilon=2.6 \times 10^{5} \mathrm{dm}^{3} \mathrm{~mol}^{-1} \mathrm{~cm}^{-1}\right] ; \quad Q(1,0) \quad\left[\lambda_{\max }\right.$ $\left.=504 \mathrm{~nm}, \varepsilon=1.6 \times 10^{4} \mathrm{dm}^{3} \mathrm{~mol}^{-1} \mathrm{~cm}^{-1}\right]$ and $Q(0,0)\left[\lambda_{\max }\right.$ $\left.=538 \mathrm{~nm}, \varepsilon=1.5 \times 10^{4} \mathrm{dm}^{3} \mathrm{~mol}^{-1} \mathrm{~cm}^{-1}\right]$ ); (4) there is a large Stokes shift between the absorption and emission spectra; (5) it has good photooxidative stability [Fig. 3(c)]; (6) it

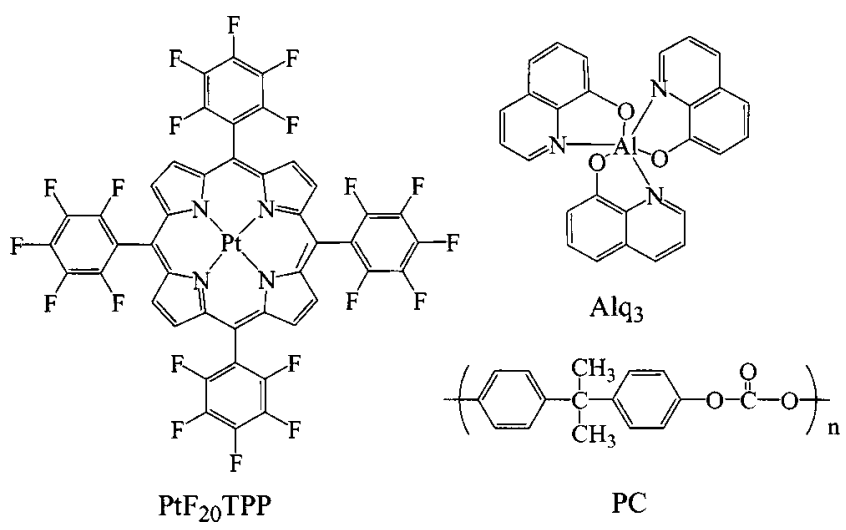

FIG. 1. The chemical structures of $\mathrm{PtF}_{20} \mathrm{TPP}, \mathrm{Alq}_{3}$, and PC. 


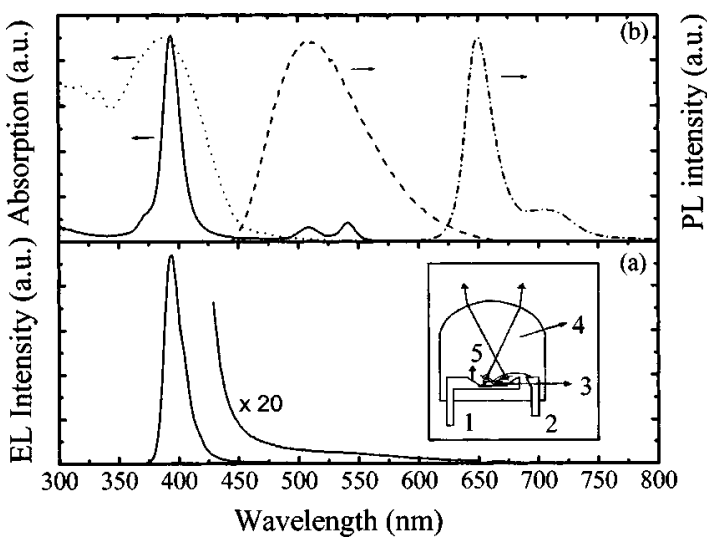

FIG. 2. (a) The EL spectrum of $n$-UV GaN-LED. Inset: schematic diagram of the $n$-UV GaN-LEDs in a transparent epoxy package: (1) anode post, (2) cathode post, (3) GaN chip, (4) epoxy lens, and (5) reflector cup. (b) The absorption spectra of $\mathrm{PtF}_{20} \mathrm{TPP}$ (solid line) and $\mathrm{Alq}_{3}$ (dotted line); the PL emission spectra of $\mathrm{PtF}_{20} \mathrm{TPP}$ (dash-dotted line) and $\mathrm{Alq}_{3}$ (dashed line).

has high thermal stability (decomposition temperature $T_{d}$ at $413^{\circ} \mathrm{C}$; there is no change in PL emission intensity after heating the $\mathrm{PtF}_{20} \mathrm{TPP}$ thin film at $120^{\circ} \mathrm{C}$ in air for $1000 \mathrm{~h}$ ); (7) the thin-film PL quantum yield of $\mathrm{PtF}_{20} \mathrm{TPP}$ is probably larger than that in solution because the rotation of phenyl groups provides a nonradiative relaxation pathway for the triplet excited state of $\mathrm{PtF}_{20} \mathrm{TPP}$; this relaxation would possibly be frozen in solid thin film. ${ }^{17}$

All thin films were prepared by spin-coating method in the following manner: (a) dissolving the dyes in chloroform along with poly(bisphenol A carbonate) (PC) (Fig. 1) and (b) dispersing the solution mixture on quartz plate, spinning the plate and baking the film at $80^{\circ} \mathrm{C}$ under vacuum for $12 \mathrm{~h}$ to form a transparent matrix film. The thickness of the film was approximately $500 \mathrm{~nm}$. All the measurements were performed at ambient temperature in air. On the other hand, red and white LC-LEDs were prepared by dip-coating method. In contrast to the reported "double layers method," 6 $\mathrm{PtF}_{20} \mathrm{TTP}, \mathrm{Alq}_{3}$ and $\mathrm{PC}$ were dissolved in chloroform to form a single layer film on the epoxy of the LED. The concentrations of the dyes were adjusted to fine tune the emission color of the hybrid LC-LEDs. The output power of the LEDs was measured by laser power monitor (OPHIR).

As depicted in Fig. 2(b), the Soret absorption band $\left(\lambda_{\max }=394 \mathrm{~nm}\right.$ as thin film) of $\mathrm{PtF}_{20}$ TPP overlaps with the electroluminescence (EL) spectrum of $n$-UV GaN-LED $\left(\lambda_{\max }=394 \mathrm{~nm}\right)$. This overlap provides a channel for efficient luminescence conversion. At first, we prepared red LCLED with $\mathrm{PtF}_{20} \mathrm{TPP}$ and $n$-UV GaN-LED only. This LED shows an impure red color emission, as shown in Fig. 3(a). The surplus of $n$-UV emission from GaN-LED affects the purity of red light, and the CIE_1931 chromaticity is shifted to $x=0.50$ and $y=0.24$. We have then tried to optimize the LED performance in two ways. The first attempt was to increase the thickness of dip-coating film and concentration of $\mathrm{PtF}_{20}$ TPP. However, the efficiency of LED was found to decrease as a result of self-quenching and self-absorption at high $\mathrm{PtF}_{20}$ TPP concentration. The second attempt was to choose a dye that can absorb the high-energy emission from $n$-UV GaN-LED and then transfer the absorbed energy to the red phosphorescent dye $\mathrm{PtF}_{20} \mathrm{TPP}$. We found that $\mathrm{Alq}_{3}$ is a good material for this purpose. The absorption spectrum of

Downloaded 08 Nov 2006 to 147.8.21.97. Redistribution subject
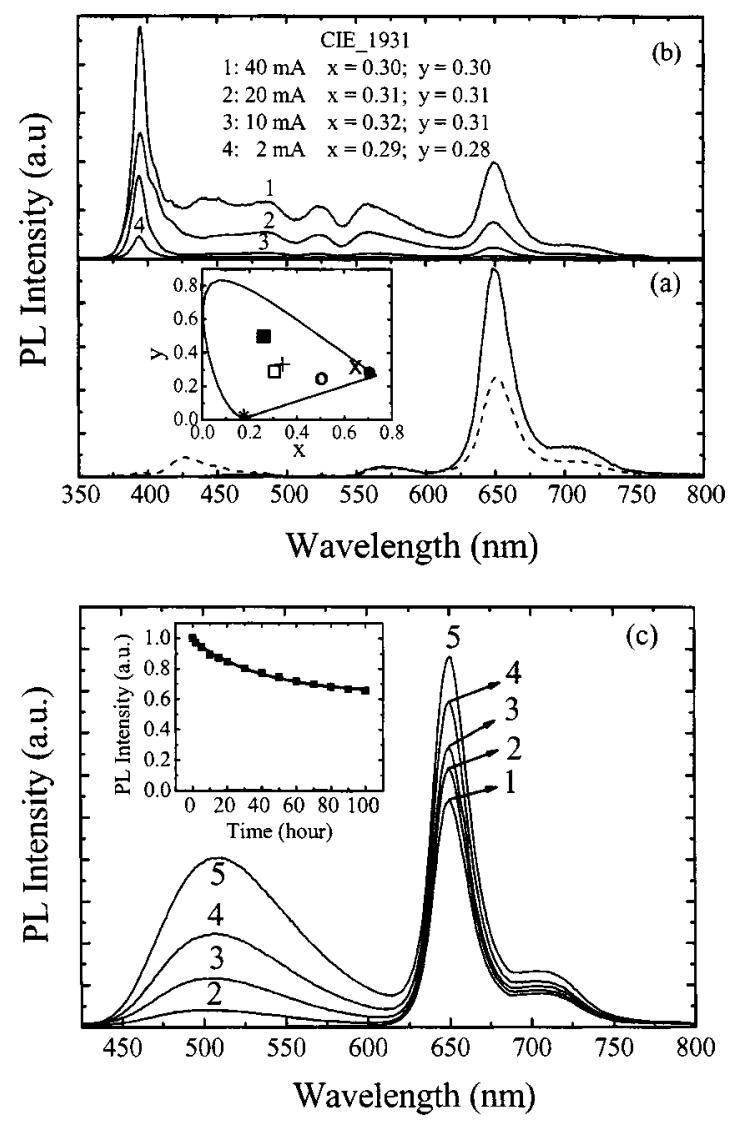

FIG. 3. (a) Emission spectra of the red LC-LED (solid line) doped with $\mathrm{Alq}_{3}$ and without $\mathrm{Alq}_{3}$ (dashed line). Inset: CIE_1931 chromaticity diagram, with coordinates corresponding to emission of the $n$-UV GaN LED $(*), \mathrm{Alq}_{3}$ thin film $(\boldsymbol{\square}), \mathrm{PtF}_{20}$ TPP thin film $(\bullet)$, red LC-LED doped with $\mathrm{Alq}_{3}(\times)$, red LC-LED without $\mathrm{Alq}_{3}(\bigcirc)$, the white LC-LED $(\square)$, and ideal pure white emission (+). (b) Emission spectra and CIE_1931 chromaticity coordinates of the white LC-LEDs under different applied currents. (c) PL spectra of $\mathrm{PtF}_{20} \mathrm{TPP}\left(1.0 \%\right.$ in PC) as thin-film doped with $\mathrm{Alq}_{3}$ (excited at $394 \mathrm{~nm}$ ); (1) 1:0, (2) 1:2, (3) 1:5, (4) 1:10, (5) $1: 20\left(\mathrm{PtF}_{20} \mathrm{TPP}: \mathrm{Alq}_{3}\right.$, by weight). Inset: photooxidative measurement of $\mathrm{PtF}_{20} \mathrm{TPP}$ film under irradiation of $1 \mathrm{~mW} / \mathrm{cm}^{2}$ at $394 \mathrm{~nm}$ in air at ambient temperature (signal detected at $650 \mathrm{~nm}$ ).

$\mathrm{Alq}_{3}$ overlaps with the EL spectrum of $n$-UV GaN-LED. In addition, the PL emission of $\mathrm{Alq}_{3}$ overlaps with the $Q(1,0)$ band $\left(\lambda_{\max }=509 \mathrm{~nm}\right.$ as thin film) and $Q(0,0)$ band $\left(\lambda_{\max }\right.$ $=541 \mathrm{~nm}$ as thin film) of $\mathrm{PtF}_{20} \mathrm{TPP}$ (Fig. 2). The PL spectra of $\mathrm{PtF}_{20} \mathrm{TPP}$ thin films doped with various concentrations of $\mathrm{Alq}_{3}$ are shown in Fig. 3(c). Increasing the ratio of $\mathrm{Alq}_{3}$ to $\mathrm{PtF}_{20}$ TPP enhances the intensity of the red photoluminescence from $\mathrm{PtF}_{20} \mathrm{TPP}$. The optimal ratio of $\mathrm{PtF}_{20} \mathrm{TPP}$ to $\mathrm{Alq}_{3}$ (by weight) is 1:5. No surplus of $n$-UV emission from $\mathrm{GaN}$ LED can be observed under this condition. The high-energy emission from GaN-LED is effectively converted to lowenergy emission through luminescence conversion. The efficiency of the red LC-LED has been found to be remarkably improved by $\mathrm{Alq}_{3}$. Also, we successfully obtained a saturated red-light LED with CIE_1931 coordinates at $x=0.65$ and $y=0.32$ [Fig. 3(a)]. The CIE chromaticity coordinates of the red LC-LED are independent of current inputs (from 5 to $40 \mathrm{~mA}$ ).

Intense high-purity white light emission has also been achieved by a similar fabrication method. By varying the ratio of $\mathrm{PtF}_{20}$ TPP to $\mathrm{Alq}_{3}$ from 1:5 to 1:40 (by weight) and the $\mathrm{PtF}_{20} \mathrm{TPP}$ concentrations in poly(bisphenol A carbonate) AIP license or copyright, see http://apl.aip.org/apl/copyright.jsp 
from $5.0 \%$ to $1.0 \%$, the $n$-UV EL emission from GaN-LED, the green emission from $\mathrm{Alq}_{3}$, and the red emission from $\mathrm{PtF}_{20}$ TPP combine to give white emission. The emission from the white LC-LED shows highly pure white color of CIE_1931 coordinates at $x=0.32$ and $y=0.31$, which is close to the ideal pure white CIE_1931 coordinates at $x$ $=0.33$ and $y=0.33$ [Fig. 3(b)]. The CIE_1931 coordinates of our white LC-LED change slightly from $(0.29,0.28)$ to $(0.32,0.31)$ upon varying the input current from 2 to $40 \mathrm{~mA}$. Under a forward bias of $20 \mathrm{~mA}$, the color temperature $\left(T_{c}\right)$, color rendering index $\left(R_{a}\right)$ and luminous efficiency $\left(\eta_{L}\right)$ of the white LC-LED are $6800 \mathrm{~K}, 90.6$ and $10 \mathrm{~lm} / \mathrm{W}$, respectively. Compared to the commercial white LED (blue LED $(\sim 460 \mathrm{~nm})+$ yellow phosphor), our white LED shows several advantages: (1) the luminous efficiency augments linearly with increasing input current (for commercial LED, the output signal of the blue-color emission tends to saturate at high input current) $;{ }^{14}(2)$ the combination of $n$-UV, green and red colors leads to lower $T_{c}$ and higher $R_{a}$ values; and (3) the CIE coordinates change only slightly with varying driving current [Fig. 3(b)]. Narukawa and co-workers recently reported a phosphor-conversion white LED using InGaN $n$-UV chip, blue and yellow phosphors. ${ }^{12}$ In this work, we employed two organic phosphors instead of inorganic materials to fabricate the white LC-LED. The red dye $\mathrm{PtF}_{20} \mathrm{TPP}$ was used to generate the red component for white emission; a higher $R a$ value (90.6) and highly pure white emission have been achieved.

In the case of a hybrid LED with a single layer, the conversion efficiency (the ratio of the number of photons emitted to the number of photons from the $n$-UV pump) is given by

$$
\eta_{c}=f_{\alpha} \eta_{\mathrm{PL}}+\left(1-f_{\alpha}\right)=1-f_{\alpha}\left(1-\eta_{\mathrm{PL}}\right),
$$

where $f_{\alpha}$ is the fraction of pump light absorbed by the dye film; $\eta_{\mathrm{PL}}$ is the PL quantum efficiency of the dye film; and $\left(1-f_{\alpha}\right)$ is the fraction of residual light from GaN-LED. For the white LC-LED with two dyes in a single film, due to the energy transfer from $\mathrm{Alq}_{3}$ to $\mathrm{PtF}_{20} \mathrm{TPP}$, Eq. (1) is modified to

$$
\begin{aligned}
\eta_{c}= & f_{\alpha, r} \eta_{\mathrm{PL}, r}+f_{\alpha, g} f_{t} \eta_{t}+\left(f_{\alpha, g}-f_{\alpha, g} f_{t}\right) \eta_{\mathrm{PL}, g} \\
& +\left(1-f_{\alpha, r}-f_{\alpha, g}\right)=1-f_{\alpha, r}\left(1-\eta_{\mathrm{PL}, r}\right) \\
& -f_{\alpha, g}\left(1-\eta_{\mathrm{PL}, g}\right)-f_{\alpha, g} f_{t}\left(\eta_{\mathrm{PL}, g}-\eta_{t}\right),
\end{aligned}
$$

where $f_{\alpha, r}$ and $f_{\alpha, g}$ are the fractions of pump light absorbed by the red dye film and the green dye film, respectively; $\eta_{\mathrm{PL}, r}$ and $\eta_{\mathrm{PL}, g}$ are the PL quantum efficiencies of the red dye film and green dye film, respectively; $f_{t}$ is the fraction of energy transfer from the green dye film to the red dye film; and $\eta_{t}$ is the quantum efficiency of the red dye film caused by energy transfer from the green dye film. For the red LCLED, all emission from the $n$-UV GaN LED is absorbed $\left(f_{\alpha, r}+f_{\alpha, g}=1\right)$ and no emission from the green dye film $\left(f_{t}=1\right)$ can be observed. Therefore, Eq. (2) is simplified to

$$
\eta_{c}=f_{\alpha, r} \eta_{\mathrm{PL}, r}+f_{\alpha, g} \eta_{t} .
$$

The $n$-UV GaN LED shows a power output of $8.0 \mathrm{~mW}$ at a current of $20 \mathrm{~mA}$ with $11 \%$ EL efficiency. Using the $n$-UV LED as pumping source, our red LC-LED has a power output of $3.0 \mathrm{~mW}$ with $4.0 \%$ efficiency at $20 \mathrm{~mA}$. This is more comparable to the literature value of $1.9 \%$ efficiency for InGaN/conjugated polymer hybrid LEDs. ${ }^{6}$ The $n$-UV-to-red conversion efficiency is $36 \%$. However, the efficiency of our red LC-LED is lower than that of AlGaAs-based red LED $(10 \%) .{ }^{19}$ This is possibly due to the absence of LED encapsulation and low efficiency of $n$-UV LED (11\% EL efficiency). Under same forward bias at $20 \mathrm{~mA}$, our white LCLED shows a power output of $2.6 \mathrm{~mW}$ with $3.3 \%$ efficiency; and the $n$-UV-to-white conversion efficiency is $30 \%$. The luminous efficiency of $10 \mathrm{~lm} / \mathrm{W}$ is obtained which is lower than that reported by Narukawa et al. ${ }^{12}$ this is presumably due to the low luminous efficiency $n$-UV LED $(0.90 \mathrm{~lm} / \mathrm{W})$. The emissions from our unpackaged red and white LC-LEDs demonstrated 50\% degradation after $1000 \mathrm{~h}$ at ambient temperature in air. We anticipate that the lifetime and brightness of the LC-LEDs described in this work can be improved by encapsulation of the dyes at the top of the GaN chip on the reflector cup using epoxy material. ${ }^{89}$ Encapsulation of LED can reduce viewing-angle dependence because the epoxy material can be used as a lens to focus the light.

In conclusion, we have demonstrated a strategy to obtain intense, highly pure white and red emissions from GaN-LED/Alq ${ }_{3} / \mathrm{PtF}_{20} \mathrm{TPP}$ hybrid LC-LEDs. The white LED has high color rendering index (90.6) at $20 \mathrm{~mA}$. This provides an impetus development for designing effective and highly pure red and white LEDs by using organic materials.

The authors are grateful for financial support from The University of Hong Kong and Innovation and Technology Commission of The Government of the HKSAR, China (Project No. ITS/053/01).

${ }^{1}$ J. P. Basrur, F. S. Choa, P. L. Liu, J. Sipior, G. Rao, G. M. Carter, and Y. J. Chen, Appl. Phys. Lett. 71, 1385 (1997).

${ }^{2}$ S. Guha, R. A. Haight, N. A. Bojarczuk, and D. W. Kisker, J. Appl. Phys. 82, 4126 (1997)

${ }^{3}$ T. Egawa, T. Jimbo, and M. Umeno, J. Appl. Phys. 82, 5816 (1997).

${ }^{4}$ T. Nishida, H. Saito, and N. Kobayashi, Appl. Phys. Lett. 79, 711 (2001).

${ }^{5}$ S. Guha and N. A. Bojarczuk, Appl. Phys. Lett. 73, 1487 (1998).

${ }^{6}$ F. Hide, P. Kozodoy, S. P. DenBaars, and A. J. Heeger, Appl. Phys. Lett. 70, 2664 (1997)

${ }^{7}$ C. Zhang and A. J. Heeger, J. Appl. Phys. 84, 1579 (1998).

${ }^{8}$ P. Schlotter, R. Schmidt, and J. Schneider, Appl. Phys. A: Mater. Sci. Process. 64, 417 (1997).

${ }^{9}$ P. Schlotter, J. Baur, C. Hielscher, M. Kunzer, H. Obloh, R. Schmidt, and J. Schneider, Mater. Sci. Eng., B 59, 390 (1999).

${ }^{10}$ R. M. Mach, G. O. Mueller, M. R. Krames, and T. Trottier, IEEE J. Sel. Top. Quantum Electron. 8, 339 (2002).

${ }^{11}$ J. Tardy and L. Berthelot, Organic Light-Emitting Materials and Devices III (The International Society for Optical Engineering, Washington, 1999), p. 399.

${ }^{12}$ Y. Narukawa, I. Niki, K. Izuno, M. Yamada, Y. Murazaki, and T. Mukai, Jpn. J. Appl. Phys., Part 2 41, L371 (2002).

${ }^{13}$ M. Yamada, T. Naitou, K. Izuno, H. Tamaki, Y. Murazaki, M. Kameshima, and T. Mukai, Jpn. J. Appl. Phys., Part 2 42, L20 (2003).

${ }^{14}$ J. K. Sheu, S. J. Chang, C. H. Kuo, Y. K. Su, L. W. Wu, Y. C. Lin, W. C. Lai, J. M. Tsai, G. C. Chi, and R. K. Wu, IEEE Photonics Technol. Lett. 15, 18 (2003).

${ }^{15}$ J. S. Lindsey and R. W. Wagner, J. Org. Chem. 54, 828 (1989).

${ }^{16}$ E. Y. Tyulyaeva, T. N. Lomova, and L. G. Andrianova, Russ. J. Inorg. Chem. 46, 371 (2001)

${ }^{17}$ R. C. Kwong, S. Sibley, T. Dubovoy, M. Baldo, S. R. Forrest, and M. E. Thompson, Chem. Mater. 11, 3709 (1999).

${ }^{18}$ C. M. Che, Y. J. Hou, M. C. W. Chan, J. H. Guo, Y. Liu, and Y. Wang, J. Mater. Chem. 13, 1362 (2003).

${ }^{19}$ R. Wirth, C. Karnutsch, S. Kugler, S. Thaler, and K. Streubel, LightEmitting Diodes: Research, Manufacturing, and Applications (The International Society for Optical Engineering, Washington, 2001), Vol. 41. 